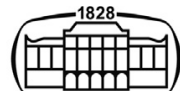

AKADÉMIAI KIADÓ

\title{
Day trip to hell: A mixed methods study of challenging psychedelic experiences
}

\author{
PETTER GRAHL JOHNSTAD* ๑
}

\section{Journal of Psychedelic Studies}

5 (2021) 2, 114-127

DOI:

10.1556/2054.2021.00155

(c) 2021 The Author(s)

\section{ORIGINAL RESEARCH} PAPER

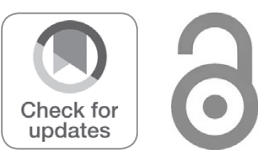

University of Bergen, Bergen, Norway

Received: September 30, 2020 • Accepted: April 17, 2021

Published online: May 26, 2021

\section{ABSTRACT}

Background and aims: This article presents a mixed methods study of challenging psychedelic experiences or "bad trips", with the aim of exploring the nature and characteristics of such experiences. While challenging psychedelic experiences have been studied in previous research, the article posits that the focus of this research has been overly narrow in terms of the characteristics and etiology of these experiences, and that it would be helpful to broaden our understanding of what a challenging psychedelic trip might be and how it affects users. Methods: In the first study, respondents $(N=38)$ were recruited at various online fora for individual anonymous interviews via private messaging. The Cannabis and Psychedelics User Survey used for the second study was constructed on the basis of the knowledge obtained from interviews, and recruited 319 participants (median age 33; 81\% male) from seven different online communities. Respondents were asked to characterize both a typical and their worst psychedelic experience, allowing for comparisons between the two and for regression analyses of associations between challenging experiences and other factors. Results: Both in interviews and in the survey, respondents reported a broader range of characteristics for challenging psychedelic experiences than what has previously been recognized in the research literature. Despite the often dramatic narratives, they were convinced that the experience had positive long-term consequences. Conclusions: The two studies found that challenging psychedelic experiences have a greater thematic range than what has previously been identified. Besides the near ubiquity of fear in these experiences, confusion was also identified as an important aspect. Meditation practice had paradoxical effects on challenging psychedelic experiences, appearing as a fruitful area for further research.

\section{KEYWORDS}

adverse effects, bad trip, interview, meditation, qualitative, psychedelic, survey

\section{INTRODUCTION}

Psychedelics are a group of psychoactive drugs with powerful effects on feelings, thought, and perception (Nichols, 2004, 2016). They include mescaline (the active constituent of the cactus peyote), psilocybin (the active constituent of "magic mushrooms"), lysergic acid diethylamide (LSD), and N,N-dimethyltryptamine (DMT), the four of which are sometimes referred to as the classical psychedelics, as well as a range of other substances (overviews of psychedelic phenethylamines and tryptamines are available in Shulgin \& Shulgin, 1991, 1997). The classical psychedelics are known for their low toxicity and are not considered to be reinforcing substances (Nichols, 2004), but some newer phenethylamines have higher toxicity (Nichols, 2016). Research on the therapeutic effects of psychedelics goes back to the 1940s, but was curtailed in the 1970s when psychedelics were designated drugs of abuse with no accepted medical applications (Cohen, 1960; Johnstad, 2020a; Rucker, Iliff, \& Nutt, 2018). After a long hiatus, this line of inquiry has been taken up again during the past decade, with preliminary results indicating therapeutic effect from psychedelics on conditions such as depression (Carhart-Harris et al., 2016, 2018; Griffiths et al., 2016; Ross et al., 2016), anxiety (Gasser et al., 2013; Griffiths et al., 2016; Grob et al., 2011; Ross et al., 2016), and substance 
dependence (Bogenschutz et al., 2015; Johnson, GarciaRomeu, Cosimano, \& Griffiths, 2014; Schenberg, de Castro Comis, Chaves, \& da Silveira, 2014; Thomas, Lucas, Capler, Tupper, \& Martin, 2013).

Psychedelics have a long history of use in religious contexts among indigenous peoples (Dobkin de Rios, 1990; Hultkrantz, 1997; Labate \& Cavnar, 2014; Maroukis, 2012), and their use have been associated with spiritual and mystical experience among modern westerners (CarhartHarris \& Nutt, 2010; Griffiths, Richards, McCann, \& Jesse, 2006; Johnstad, 2018; Lyvers \& Meester, 2012; Pahnke, 1966). This association may in part be explained by the finding that psychedelics sometimes induce experiences of ego dissolution in which users feel a sense of union with other people and with the universe (Nour, Evans, Nutt, \& Carhart-Harris, 2016). Furthermore, some researchers have argued that the therapeutic effects of psychedelics may, unlike most other therapeutic drugs, depend at least in part on their experiential effect, and especially on effects related to ego dissolution and a sense of connectedness (CarhartHarris, Erritzoe, Haijen, Kaelen, \& Watts, 2017; Majić, Schmidt, \& Gallinat, 2015).

However, not all psychedelics users are comfortable with experiencing the dissolution of their ego or self, and this effect can therefore lead to intense fear as users feel they are losing their sanity or are about to die. Researchers have attempted to measure this effect with a rating scale named Dread of Ego Dissolution (DED), which covers experiences of cognitive impairment, loss of self-control, feelings of disintegration or separation from oneself and the world, and anxiety or panic (Studerus, Gamma, Kometer, \& Vollenweider, 2012). High scores on the DED scale may therefore be understood as an indication of an unpleasant psychedelic drug state, or in other words a "bad trip". However, Barrett, Bradstreet, Leoutsakos, Johnson, and Griffiths (2016) criticized the DED scale for overlooking some categories of challenging experiences, and constructed a scale based on a questionnaire of psilocybin experiences with seven categories or factors: grief, fear, death, insanity, isolation, physical distress, and paranoia. Thus, while one type of challenging trip may result from fearful resistance to the psychedelic effect of ego dissolution, others may be quite different in terms both of their characteristics and their etiology.

While researchers have generally been unable to identify predictors for adverse psychedelics experiences (Rubinow \& Cancro, 1977; Ungerleider, Fisher, Fuller, \& Caldwell, 1968), it has long been recognized that the effects of psychedelic drug use are highly dependent on the factors of "set and setting", where "set" refers to the user's personality, preparation, expectation, and intention at the time of drug administration and "setting" to the physical, social, and cultural environment (Hartogsohn, 2017). Lucas (2005) summed up four rules of common sense for psychedelic trips, finding that

any of the following could lead to a bad trip: (l) taking psychedelics when you are troubled about something; (2) taking them in an environment with people you do not trust;
(3) taking them in an over-stimulating environment like a public place; or (4) taking too much (Lucas, 2005, p. 26).

In the psilocybin study by Studerus et al. (2012), the predictors for DED were high drug dose, being placed in a positron emission tomography (PET) scanner, and an indicator called "emotional excitability" that assessed the mental state before drug administration. What tended to cause difficult experiences, in other words, were two variables for a specific set and setting added to the unsurprising fact that higher psychedelic doses were found to be more challenging. These three factors were also central to the findings of an online survey of 1993 individuals about their most difficult or challenging psilocybin experience (Carbonaro et al., 2016). In this survey, higher psilocybin dosage increased the difficulty of the challenging trip, as expected, but, somewhat surprisingly, the use of cannabis or other drugs before or during the session was found to decrease the difficulty. In fact, some users commented that they smoked cannabis to deal with their challenging trip, although others noted that cannabis exacerbated the difficult experience. Besides these matters of dosage and drug combinations, factors related to set and setting - the emotional state before ingestion, the physical comfort of the setting, and the availability of social support during the session - also had a significant impact on the difficulty of the experience. Furthermore, mature and experienced users were generally better able to deal with the experience. One smaller survey of extra-pharmacological factors in the etiology of "bad trips" found that recreational use, large outdoor spaces, and user inexperience were associated with challenging experiences (Ona, 2018).

It seems, therefore, that set and setting are important for the outcome of a psychedelic trip. Whether they are sufficient to avoid a bad trip is another matter. Both Rubinow and Cancro (1977) and Ungerleider et al. (1968) acknowledged the helpfulness of an appropriate set and setting, but they also warned that precautions in this regard do not guarantee against adverse reactions. Lucas (2005) noted that bad trips can happen even when you follow all the rules of common sense, and criticized what she called the "set-andsetting attitude" as playing into a Western fantasy of control: "if we just do everything right, we can prevent negative experiences" (p. 26). Instead, she understood psychedelic bad trips as a shamanic initiation experience involving the dismemberment of inauthentic parts of the self.

This perspective on challenging trips as valuable learning experiences has been shared by both researchers and members of the psychedelic community. A large majority (84\%) of the respondents to Carbonaro et al.'s (2016) survey endorsed having benefitted from the challenging trip, even as they also often reported that it was one of the most difficult experiences of their lives. Majić et al. (2015) suggested that the benefits of adverse psychedelic experiences might include therapeutic effects, as painful psychodynamic reactions are often considered fruitful in a psychotherapeutic context. However, they also noted that difficult experiences involving psychotic reactions might have anti-therapeutic 
consequences. Lucas (2005) suggested that psychedelic bad trips only have valuable developmental and therapeutic effects when the user is willing and able to integrate their hard lessons, which may require the presence of wise and trusted counsel.

To sum up the state of current knowledge, it seems fair to say that the characteristics, etiology, and consequences of psychedelic "bad trips" remain somewhat unclear. Fear of death or insanity accompanying states of ego dissolution seems to play a central role, but probably does not account for all difficult experiences. Indeed, if we start from the assumption that challenging psychedelic experiences may be as varied as other forms of challenging experiences, even the seven categories identified by Barrett et al. (2016) may be too limited. Set and setting are clearly important, but have perhaps been overemphasized. Consequences seem largely benign, but perhaps only when the challenging experience is worked with in fruitful ways. The purpose of the present study was to expand our understanding of the characteristics of the challenging psychedelic experience, and to test previously established findings about their etiology and consequences. Its working hypotheses were that challenging psychedelic experiences have a greater thematic range than what has been established in previous research, that set and setting are important but not decisive, and that respondent-assessed consequences are generally positive.

\section{METHOD}

In the interview study, 38 current or past psychedelics users were interviewed about their experiences in two phases of study. In the first phase, 26 users of psychedelic drugs in spiritual contexts were interviewed either individually or in groups about a broad range of aspects relating to their psychedelics use. These interviews always touched upon the subject of challenging trips, although not all responses opened up for a deeper investigation of the subject. In order to gain more insight, a second phase of study recruited 12 users specifically on the basis of their reports of challenging psychedelic experiences posted on Internet discussion fora. These 38 participants gave their informed consent to be included in the study. In addition, the study was informed by a number of "bad trip" reports posted on discussion fora by users who were either currently unreachable or who did not reply to recruitment attempts. These reports were often of considerable value to the study, but in order to preserve the privacy of their authors, the reports have not been quoted from in the article. Interviewees in the study often resisted the notion of a "bad trip", preferring instead to refer to this as challenging experiences, and this terminology is adhered to in the presentation.

Interviews were asynchronous and Internet-mediated, and participants were encouraged to interact with the interviewer via anonymized email or messaging that protected their identity from the researcher. The study was designed in conformity with Norwegian Social Science Data
Services ethical guidelines. It emphasized the preservation of participant anonymity, and aimed to ensure that no participant would be identifiable either to the researcher or to readers of published material. A few quotations have been translated from Norwegian, and statements have been edited for brevity and relevance. Insignificant details have sometimes been altered to preserve anonymity, and participants were asked to read through and verify the use of their quotations in their final form. As interviews took the form of written communication, transcription was unnecessary. Data were analyzed using thematic analysis (Braun \& Clarke, 2006) and Kvale and Brinkmann's (2015) procedure for meaning condensation, and themes were constructed in an open-ended, exploratory, and data-driven comparative analysis of participant narratives. The interview process allowed for the resolution of ambiguities through follow-up questions.

The Cannabis and Psychedelics User Survey was constructed on the basis of the interview study, with questions and the range of possible survey responses being based on themes identified in the interview analysis. Before the survey was deployed, it went through a round of asynchronous testing on 18 volunteers recruited online, although this resulted only in minor revisions. The survey was made generally available online via SurveyXact from April to September 2019 for self-selected participation. It was fully anonymous and recorded no identifying participant information, including IP addresses. Several articles based on the Cannabis and Psychedelics User Survey have been published or submitted for publication (Johnstad, 2020c, 2021a-e), and the dataset and survey questionnaire are available for download via figshare (Johnstad, 2020b).

Participants for the survey were obtained from seven communities: www.shroomery.org, www.dmt-nexus.me, www.bluelight.org, the Facebook page for Portland Psychedelic Society, the Reddit group r/Psychedelics, the Norwegian Association for Safer Drug Policy, and an informal group of psychedelics users in Bergen, Norway. Participants were recruited either via invitation threads started at each forum or via a snowballing email invitation. Women were especially invited to participate in the survey. The only inclusion criteria were adulthood (18 years or older), the ability to understand English well, and experience with a commonly used psychedelic drug. Individuals who did not meet the inclusion criteria were linked to a shorter version of the survey, and their data were not used in the analyses. Respondents reported using between 10 and 30 minutes to complete the survey.

\section{Measures}

The Cannabis and Psychedelics User Survey included basic demographic questions relating to age, gender, education, work status, and relationship status. Gender was measured with three categories (female, male, and other), but when the gender variable was used as a control in statistical analyses, seven participants who indicated an "other" gender were excluded from the analysis. Education was quantified from 1 
$=$ "Have not completed high school" to $6=$ "PhD". Participants were also asked about their religious or spiritual background and their present religious or spiritual affiliations, as well as their current spiritual practice. Further questions examined their usage history and/or present use of cannabis and the psychedelic drugs of the $2 \mathrm{C}$ family (2C-B [2,5-dimethoxy-4-bromophenethylamine] etc.), 5-MeODMT (5-methoxy-N,N-dimethyltryptamine), Ayahuasca (or analogues), smoked DMT (N,N-Dimethyltryptamine), LSD (Lysergic acid diethylamide), MDMA (3,4-Methylenedioxymethamphetamine), Mescaline/Peyote, Psilocybin/Magic mushrooms, and Salvia divinorum. The survey asked participants to choose one psychedelic drug from this list that they had experience with, and they were queried about their motivations for the use of this drug and asked to characterize emotional, cognitive and relational aspects of their most meaningful experience with the drug, of a typical experience, and of their worst experience.

In order to measure the personality of the participants, the survey included a version of Gosling, Rentfrow, and Swann's (2003) Ten-Item Personality Inventory (TIPI), measured on a five-level Likert scale from "disagree strongly" to "agree strongly". The TIPI is a concise measurement tool with only two items for each Big Five trait, but has been shown to have adequate construct validity, testretest reliability, and patterns of external correlates (Gosling et al., 2003). The survey also included a version of Nicholson, Soane, Fenton-O'Creevy, and Willman's (2005) Risk Taking Index (RTI), measured on a five-level scale from "never" to "very often". The original RTI contained an item for health risk that related to substance use, and to adapt the scale to a sample of cannabis and psychedelics users this item was removed. Thus, the modified RTI used for this survey included only five items: recreational risk, career risk, financial risk, safety risk, and social risk. See Johnstad (2021e) for a more detailed discussion of how personality measurement tools were modified for the Cannabis and Psychedelics User Survey.

\section{Statistical analysis}

To predict the difficulty of a challenging psychedelic experience, an ordinal regression analysis used survey respondents' characterizations of their worst psychedelic experience as the dependent variable. The survey presented a list of 24 emotional, cognitive, and relational characteristics, each of which the respondent could endorse or not endorse on a dichotomous basis as applying to their worst experience with psychedelics. Eight of these were negative items - anger or hate, confusion, disgust, fear, feeling of isolation from other people, regrettable behavior towards others, sadness, and violent behavior - all of which received a higher level of endorsement for the respondents' worst experience than for a typical psychedelic experience (Table 2). To construct a variable indicating the difficulty of a psychedelic experience, these eight negative items were added together (variable range $0-8$ ). Ordinal regression was used to assess the impact of a range of predictor variables on this additive variable while controlling for commonly used demographic covariates (Hendricks et al. 2015; Nour, Evans, \& Carhart-Harris, 2017) as well as the Big Five personality traits and the overall risk taking score (RTI). In this model, the independent variables were gender (coded as female $=0$, male $=1$ ), age, education, the six personality traits, three dichotomous variables for spiritual practices involving meditation, prayer, and energy work (having such practice $=1$ ), years of cannabis experience (coded from $1=$ "Less than a year" to 5 $=$ " $10+$ years"), the lifetime number of use occasions with the psychedelic chosen for the survey (coded from $1=$ " 1 " to $8=$ " $101+")$, a five-level ordinal variable for the social environment in which respondents most commonly used their chosen psychedelic (coded from 1 = "Alone", $2=$ "With a single partner", 3 = "With a small group of close friends", 4 = "With a group of friends and acquaintances", and $5=$ "At a party, night club, concert, festival or other public event"), an ordinal variable for how long the psychedelic session was planned in advance (coded from $1=$ "One day or less" to $5=$ "A year"), and a dichotomous variable for whether or not the respondent endorsed having an escapist motivation for their psychedelics use (yes $=1$ ). The same set of independent variables were used in an ordinal regression model that analyzed the relative difficulty of the respondents' worst psychedelic experience as compared to other difficult life experiences (coded from $1=$ "Most difficult experience of your life", 2 = "Among the five most difficult experiences of your life", 3 = "Among the ten most difficult experiences of your life", $4=$ "The most difficult experience of a year", $5=$ "The most difficult experience of a month", and $6=$ "An everyday experience/ not difficult"). Finally, a linear regression model analyzed the impact of the same set of independent variables, plus the additive variable indicating the difficulty of the experience, on the respondent-assessed long-term consequences of the respondents' worst psychedelic experience (coded as a fivelevel Likert variable from 1 = "Negative", 2 = "Mostly negative", 3 = "No impact or mixed", 4 = "Mostly positive", and $5=$ "Positive"). In these analyses, ordinal variables were treated as continuous. Data was analyzed with IBM SPSS Statistics 25.

\section{RESULTS - INTERVIEW STUDY}

\section{Participant characteristics}

Because psychedelics use is generally illegal, not all respondents were willing to provide demographic information. In order to reduce participation stress, only a minimum of such information was requested. Of the 30 participants who provided their gender and age, 28 were male and two female. The median age was mid-30s, with a range from the early 20 s to the late 50 s. Six were married (three with children), seven were in stable relationships (one with children), nine were single, one divorced, and one in the middle of a breakup. Eighteen held steady jobs in retailing, education, music teaching, journalism, industrial services, IT consulting, 
carpentry, investment client support, and as a hospital worker, one was a business owner, one was an artist, four were students, one was unemployed, and one was recently disabled because of an inherited condition.

\section{Types of challenging psychedelic experiences}

Respondents reported a broad range of challenging psychedelic experiences. In many reports, the etiology and theme of the experience were clearly connected, as in cases of unpleasant insight into current life issues. In other cases, there was no obvious explanation for the challenging experience, but a comparative analysis of different reports sometimes yielded commonalities that may serve as tentative explanations. Narratives presented in this section have been categorized into different types or themes, but it should be noted that challenging experiences were sometimes the product of several converging themes that may have served to reinforce each other.

Life issues. One common form of challenging experience involved unpleasant insights about one's life. While uncomfortable at the time, these insights sometimes led to important changes. One psychedelics user, for instance, described a "so-called bad trip" from 20 years ago that focused on his habit of amphetamine use, and which made him quit amphetamines from that day. However, some users also described apparent insights that were actually delusionary, turning minor issues into huge problems. One respondent described how he was sometimes confronted with personal traumas when tripping, and emphasized the therapeutic potential of this confrontation:

Traumas can show up with no warning, especially when an episode triggers old memories. I like to call tripping a kind of cosmic dive - you never know what will be brought to the surface. But wow! talk about therapeutic potential. (ID20)

Social paranoia. Also commonly reported as an aspect of challenging experiences were thoughts that other people do not like, accept, or approve of the user. Such experiences usually occurred when respondents used psychedelics in an unfamiliar social environment. Paranoid ideation sometimes also involved the prospect of the police arriving to arrest the psychedelics user, and, more generally, that the physical world was hostile and malicious.

Troubling visions. Psychedelics often affect how users perceive their surroundings, and in challenging experiences, these distortions may take on a menacing quality. One person reported that stains on the walls would turn into moving insects and faces in pictures would display anger, while another looked out of a window and saw that the trees had eyes and were staring back at him. Some also reported threatening inner visions:

In my vision I am flying slowly and timelessly into a whirlpool that is made entirely of emaciated-looking bodies like you would see in a Nazi concentration camp, but with eyes open and staring. I am being sucked into this horror in a timeless way, and I totally freaked out. As I was going in, I was sensing cold flesh, and parts of my body were aching and I freaked out! I should also say that the period when this happened was terrible. My life was very fucked up and I was working this terrible job in a factory sweat shop. So I had a lot of sadness in me. I regretted for years not going with the vision into the whirlpool of death. The experience freaked me out so much that it kind of made me fear tripping with eyes shut, and I think I also put blocks up to inner visions. But I wrote about it for a dissertation in art school, and it really inspired me in lots of ways regarding what books I got, my ideas for art etc. I am now over that fear, but there must always be awe. Ecstasy is very alive, awesome, and wild, and cannot be tamed. (ID17)

We find in this narrative also an example of how participants in the study worked to integrate challenging experiences, and claimed to benefit from them in the long run. Other reports of troubling visions involved evil or malicious entities. DMT users in particular often reported finding themselves in an alien environment surrounded by entities that seemed to have hostile intentions:

I was shown a frightening entity and within its tentacles was my human self. Not only me but many others as well. It was unreal. It was as if it were feeding on our souls. I was enveloped within its tentacles as if it were absorbing me and the others in its grip. (ID15)

In this case, the respondent understood that the malicious entity represented his frustration, anxiety, and anger, and that he could free himself from the entity's grip by releasing his anger, but others reported seeing entities they regarded as external to themselves. Furthermore, some reports involved alterations to other senses than vision. One individual described a nightmarish vision of rapists and angry dogs, and reported that he could feel the tactile sensation of the dogs' teeth tearing his flesh and the rapists penetrating his anus.

Mental and sensory overload. Psychedelics may enhance or stimulate certain aspects of cognition and perception. This is often regarded as a desirable effect, but respondents sometimes reported that the enhancement effect was uncomfortably strong, leading to states of mental and sensory overload. One user reported that he found himself rethinking every single thought he ever had in his life at the same time, which overwhelmed him. Such overload experiences commonly resulted in confusion and an inability to think straight:

On my previous mushroom trip I got reckless. The company I worked for had just filed for bankruptcy, so my professional future was less than crystal clear. In addition I was tired and worn down after work, and the place wasn't heated properly. At the point where the trip peaked, it felt more intense than ever - in a negative sense. It was like I had been poisoned. Everything was just an out-of-control carousel of confusing chaos, thoughts, and physical discomfort. (ID18)

This individual tried to calm down using meditation techniques, but did not succeed with this. In the end, he 
managed to maneuver through the challenging trip by interacting with his friends and directing his focus away from inner experience. Another respondent described an intense experience of cognitive overload where he relived several years of his life after taking 4-HO-MiPT (4-Hydroxy$\mathrm{N}$-methyl-N-isopropyltryptamine):

I lay down, close my eyes, and immediately get a rushing feeling, like I'm in some kind of cosmic wind, blowing me out of my body. In front of me is a rotating gothic chrysanthemum. I'm only looking at this for what feels like a second or two, and then it rotates, crystalizes, and opens up, hurtling me into absolute darkness. I see light in the distance, I rush toward it. . then open my eyes, sitting in class on the first day of ninth grade. Time speeds up, and I'm in tenth grade, having a conversation with my friend. I'm still absolutely astonished, but I have some memory of laying down in bed, while tripping, before this happened. I try to open my eyes but. . I I can't. Thankfully, I don't freak out. I gather myself, realize this is some kind of effect of the drug, and that I should try to pay attention, and see what it has to offer. The headspace was more or less like watching a movie, I was just my present self watching my actions through highschool me eyes. I won't go into details about what I saw, but suffice to say I relived all of high school. A few parts were at normal speed, some parts were at double speed, but most of it went by very quickly, at something like $4,000 \times$ speed. (ID04)

As he came out of this experience, he noticed that only 15 seconds had passed since he laid down, meaning that his visions covering several years had taken place in a period of seconds. He then started to worry that he was having a psychotic break, but managed to calm himself, and did not have any lasting complications from the experience.

Ego death. Psychedelics are well known for their dissolution of the user's sense of having a separate self or ego, and this effect was sometimes experienced as threatening and distressing. Respondents who experienced fear of ego death often resisted the process of dissolution as if their lives and sanity depended on it. The relationship between ego death experiences and fear was not straightforward, however. One respondent described the process of psychedelic-induced ego death like this:

I was "crushed" out of existence. At the beginning of the experience an amorphous gray "cloud" was slowly descending toward my reclining body, and I somehow knew that when it reached me, I would be crushed. Indeed I was. It was a strong ego death experience, but once the ego was gone, it was very ecstatic. In my experience, the process of ego loss can sometimes be difficult, but it seems it's the ego that experiences fear, and once the ego is gone, there is no fear. (ID01)

Thus, it seems that while fear often accompanies the process of ego dissolution, the completion of the process dissolves not only the ego but also ego-based fear. As we will see below, the respondent quoted here also reported feeling protected by ego loss during other intense psychedelic experiences. Another user described a lasting ego dissolution effect after using cannabis, where he for several days understood his true identity as a kind of spiritual force that was only playing at being "himself". He now found that he had to make a conscious effort to keep up this charade or game, and worried that if he did not manage to keep playing the game, he would disappoint his mother and father and perhaps be labeled a schizophrenic.

Mental and physical damage. Another common cause for consternation among psychedelics user was the apparent insight that the state they were in was somehow damaging to their mental or physical health. One user reported an experience where he tried to recall old memories, but as he remembered them it was as if they were deleted and he could not access them anymore; he feared those memories were lost forever. Another described an acute fear of brain damage:

On LSD I reached a state where I felt that I somehow had lost my capacity to feel and to love, and it occurred to me that this loss might be permanent - that I had somehow fried my brain. In retrospect, I see that this fear was probably caused by earlier exposure to anti-drug propaganda. I went deeply into a state of self-contempt and full panic, fearing I was going insane. I got through it, but it was horrible. (ID19)

Some psychedelic experiences were so intense that users feared they would never be able to go back to the person they were before the experience. The respondent quoted above as having his sense of self crushed also reported an experience of seeing too much, fearing that the knowledge he had gained access to was not compatible with a continued existence as a sane person:

I felt the presence of emotionless entities with a mechanical quality about them. They wanted to show me something. I'm still not sure what it was, but my interpretation was that they were trying to show me how our reality is "constructed". There is another reality "behind" ours, and they began to show it to me by "deconstructing" my reality. What I saw shocked me. I was not prepared to see how things worked. My illusions about reality were shattered. And I was still fully "me", so I didn't have the security blanket that ego-loss often provides. As I was witnessing these things, I thought "Having seen what I've seen, there's no way I'll ever be able to return without going completely insane." I was convinced that I had gone too far, and that I wouldn't be going back. (ID01)

Upon returning to his usual state of consciousness, this respondent was relieved to discover that he had forgotten the details of his dangerous insight, and he was able to continue his life much as before. It is interesting to note that in his own view, one reason that the experience was so difficult was that he had not gone through a process of ego dissolution, and was therefore deprived of the security blanket that ego loss might have offered.

The fear of mental and physical damage often occurred along with distressing bodily sensations, and would sometimes lead to the belief that one was dying. This was especially common in cases of accidental or thoughtless 
overdosing, often because of combining different psychedelic drugs. One respondent reported a difficult experience caused by a combination of synthetic mescaline hydrochloride and 4-AcO-DMT (O-Acetylpsilocin):

My mental state became saturated with a very tangible feeling of darkness, impending doom, despair and hopelessness. I felt weak, and lying there felt like something between a decaying old corpse and an aborted human fetus. It really felt like I was poisoned, and in a great deal of danger. My blood pressure was very high, and I was getting painful twinges in my heart and some weird electric twinges in my brain. Heart attack or seizure really seemed imminent. . . it was like my system was being worked to the very point of collapse, and it felt like death could occur at any moment. (ID16)

It is impossible to say whether these experiences represented cases of actual bodily peril, or if they were panic attacks based on a form of paranoid ideation that interpreted unfamiliar mental or bodily sensations as signs of grave danger.

Time distortions. Time loops or mental loops are experiences of time going in a circle, where one feels stuck in the loop, going through the same experiences, thoughts, and emotions on repeat. One time loop experience involved an inability to form memories:

The trip was going ok but at one point I felt like I got in a loop where I could not form memories. I started worrying about memories not forming and realized I could not tell how long this has been going on. Had I been like this for months? Would it ever end? (ID02)

This experience was the result of an intentional combination of Peganum harmala and a large dose of psilocybin mushrooms. Another respondent accidentally combined LSD, cannabis, and a strong $200 \times$ extract of S. divinorum, and found himself trapped in a tiny period of time on endless repeat:

Mentally (and this is all, essentially, metaphor), my consciousness became a Planck time. For reference, that's $5.39 \times 10^{-44} \mathrm{~s}$. I became a personified version of that. It felt like I was a grain of sand on the crest of a wave that was hitting a shore. Every time the wave hit the shore, it created the universe at that particular moment, and the wave hit the shore a near infinite amount of times until the random arrangement of sand/Planck time units was just right, and then it repeated the cycle over and over again. I became one of these grains, and it was horrifying. It was hell. Hitting the shore, over and over and over again, begging to be freed. I could tell that there were other things like me around me, but I couldn't perceive anything about them besides that they were trapped eternally the same way I was. (ID04)

Another respondent drank a self-made tea based on Mimosa tenuiflora and P. harmala and described entering a void where there was nothing except his self-consciousness. He found himself utterly alone in this void of uncaring eternity, spending years or decades in a state that he described as being permeated with fear and endless despair.
A third respondent smoked a medium dose of DMT on top of a large dose of psilocybin mushrooms, and felt himself alone in a void surrounded by a noise that sounded like a wolf howl. He understood this as the sound of his soul being torn apart, and he found himself trapped feeling only horror and hopelessness for what he described as an eternity. Trying to escape from the experience by opening his eyes, he discovered that his eyes were gone. Finally, after taking a large dose of Psilocybe semilanceata and sharing a cannabis joint with his friends, a fourth respondent experienced what he referred to as a psychotic episode that also involved a feeling of eternal damnation:

I walked out on the balcony to gaze at the sky. Star signs were forming before my eyes. I believed it was the end of the world, the great dimensional shift - judgment day was upon us and I would soon have to stand trial for my sins. For some reason I believed that my girlfriend was in the neighbors' apartment and needed rescuing, so I climbed over to their balcony and started banging on the window. The neighbors were horrified. My friend tried to stop me, but it seemed to me that he was sent from the devil to stop me from fulfilling my sacred mission. So I punched him straight in the face. He fell down and there was blood everywhere. The next thing I remember is that I tried to break their window. If I could only rescue my girlfriend then both of us would be picked up by a UFO and we would be safe. The neighbors screamed as I used whatever I found to break into their home. Before I got anywhere, the apartment filled up with a flock of vampires, who descended upon me with cruel smiles and black eyes. If there is an emotion that kicks in when you give up life and accept eternal damnation, that is what I felt. The vampires put me in a UFO that flew through time and space at the speed of light, and a few hours later I woke up in the emergency ward. It was the low point of my life. The first six months after the incident I was seriously traumatized and basically a nervous wreck. (ID20)

Despite the significant legal and social repercussions resulting from this experience, the respondent felt that the episode helped him deal with his long-standing psychological problems, and he did not have any further psychotic episodes.

\section{Finding the way back}

As we have seen, challenging psychedelic experiences come in a wide variety, and suggestions for how to integrate such an experience naturally depend on its nature. One thing everyone in this study had in common, however, is that they shared the experience with their psychedelic peers on an online forum. For some, the act of writing a report of one's difficult experience and getting feedback from people who may have been in a similar situation was an explicit step in the process of integration. Others emphasized the return to normal life as a way to integrate the challenging experience. When the challenging aspects of the trip related to various life issues, respondents often spent a long time feeling their way around these issues and trying to implement necessary changes. Several respondents emphasized that difficult psychedelic experiences can teach you a lot, and that the best 
strategy for dealing with such experiences may be to accept them as they come.

I think returning to everyday life, doing ordinary things, spending time with friends and family, etc. all contribute to the integration process. (ID01)

Writing out the trip here at the forum immediately made me feel better. (ID03)

Whatever you get in the trip, just observe it and learn from it. Be grateful for every difficult and hard trip because they are the ones that teach you the most. Once you start doing this, it doesn't matter anymore whether the trip is a 'good' or a 'bad' one. It just is what it is. (ID22)

For respondents who underwent especially high-intensity experiences such as those involving the feeling of eternal damnation, the path back to normality often involved talking to a partner or family member who could reassure the user that everything would be fine and help them calm down. Some, however, lacked a trusted confidant for their psychedelic misadventures, and instead pleaded for help at online discussion fora. A number of respondents also emphasized the importance of spiritual practices such as breathing exercises and meditation in guiding a psychedelic trip out of negative territory:

I had an experience a couple of years ago where I was getting lost in the chaos of the experience and the chaos in my own mind. When I started to chant, the chaos disappeared and everything became more harmonious. Meditation can also be a way to center yourself and to find inner peace and calmness. (ID21)

When I get anxious or feel out of it in some way, either when tripping or sober, it helps to focus on the breath and try to calm it down. (ID23)

\section{RESULTS - QUANTITATIVE SURVEY}

\section{Participant characteristics}

A total of 527 forms were submitted, but 202 of these were empty or near-empty and were excluded from analysis. Six responses with substantial discrepancies on repeated drug use assessments were also excluded. Of the 319 included participants, 213 completed the full survey, while 106 opted out from parts of it. An overview of participant characteristics for the survey is provided is Table 1. The typical participant was a male aged 32 with some university education, unmarried and childless but with a partner, situated in North America and working a full time job.

The most commonly chosen psychedelic drug for the survey was psilocybin (49\%), followed by LSD (22\%) and DMT (12\%). Participants reported a generally moderate usage pattern for their chosen psychedelic drug, with the median participant having had between 1 and 10 use occasions over the past 12 months. A minority of $7 \%$ reported 11-50 use occasions over the last 12 months, indicating a range of use from between once per month to about once
Table 1. Survey participant characteristics ${ }^{\mathrm{a}}$

\begin{tabular}{|c|c|}
\hline Age in years & $\begin{array}{c}10 \% 18-19,31 \% 20-29,30 \% 30- \\
39,15 \% 40-49,9 \% 50-59,4 \% 60+ \\
(\text { Median }=32)\end{array}$ \\
\hline Gender & $17 \%$ female, $81 \%$ male, $2 \%$ other \\
\hline Relationship status & $\begin{array}{c}46 \% \text { single, } 29 \% \text { partner, } 25 \% \\
\text { married, } 1 \% \text { widow }(\mathrm{er})\end{array}$ \\
\hline Number of children & $\begin{array}{c}69 \% \text { none, } 12 \% \text { one child, } 14 \% \text { two } \\
\text { children, } 6 \% \text { three or more } \\
\text { children }\end{array}$ \\
\hline Education & $\begin{array}{c}4 \% \mathrm{PhD}, 15 \% \text { Master's degree, } 22 \% \\
\text { Bachelor's degree, } 35 \% \text { some } \\
\text { university, } 19 \% \text { high school, } 5 \% \\
\text { not completed high school }\end{array}$ \\
\hline Religious background $^{\mathrm{b}}$ & $\begin{array}{l}\text { 10\% Buddhist, 22\% Christian, 3\% } \\
\text { Hindu, } 2 \% \text { Jewish, } 2 \% \text { Muslim, } \\
15 \% \text { New Age/Alternative, 35\% } \\
\text { Secular/Humanist, } 43 \% \text { other }\end{array}$ \\
\hline $\begin{array}{l}\text { Religious affiliation at } \\
\text { present }^{\mathrm{b}}\end{array}$ & $\begin{array}{l}29 \% \text { Buddhist, } 18 \% \text { Christian, } 12 \% \\
\text { Hindu, } 5 \% \text { Jewish, } 4 \% \text { Muslim, } \\
27 \% \text { New Age/Alternative, } 42 \% \\
\text { Secular/Humanist, } 44 \% \text { other }\end{array}$ \\
\hline Occupation $^{\mathrm{b}}$ & $\begin{array}{c}55 \% \text { full time job, } 18 \% \text { part time } \\
\text { job, } 21 \% \text { student, } 3 \% \text { pensioner, } 7 \% \\
\text { unemployed, } 15 \% \text { other }\end{array}$ \\
\hline $\begin{array}{l}\text { Geographical location at } \\
\text { present }\end{array}$ & $\begin{array}{c}52 \% \text { North America, } 31 \% \text { Western } \\
\text { Europe, } 8 \% \text { Oceania, } 4 \% \text { Eastern } \\
\text { Europe, } 2 \% \text { South America, } 1 \% \\
\text { Middle East, } 1 \% \text { Asia, } 1 \% \text { Africa }\end{array}$ \\
\hline
\end{tabular}

Note: $N=319$.

${ }^{a}$ Sums may differ from $100 \%$ because of rounding.

${ }^{\mathrm{b}}$ Sums to more than $100 \%$ because respondents could choose several alternatives.

per week, while two per cent of participants reported use up to twice per week or more.

\section{Characteristics of challenging psychedelic experiences}

Participants were asked to characterize emotional, cognitive and relational aspects of their worst and a typical experience with their chosen psychedelic drug. They reported significant differences between their worst experience and a typical experience on 23 of 24 characteristics, with the only exception being ego death or dissolution (Table 2). Eight of the 24 characteristics were negatively worded - anger or hate, confusion, disgust, fear, feeling of isolation from other people, regrettable behavior towards others, sadness, and violent behavior - and these were the only items endorsed at higher levels for the worst experience than for a typical experience.

To analyze the variation in challenging psychedelic experiences, an indicator of the difficulty of the psychedelic experience was obtained by summing together the eight negative characteristics (variable range $0-8$ ). This indicator had a mean value $=2.7(\mathrm{SD}=1.8)$, suggesting that the average worst experience was only moderately difficult. Some $14 \%$ of respondents endorsed none of the negative characteristics as applying to their worst psychedelic experience, which seems to imply that they have never had a 
Table 2. Comparisons of a typical and the worst psychedelics experience

\begin{tabular}{|c|c|c|c|}
\hline & $\begin{array}{c}\text { Typical } \\
\text { psychedelic } \\
\text { experience }\end{array}$ & & $\begin{array}{c}\text { Worst } \\
\text { psychedelic } \\
\text { experience }\end{array}$ \\
\hline Anger or hate & $2 \%$ & $* * *$ & $11 \%$ \\
\hline Confusion & $24 \%$ & $* * *$ & $62 \%$ \\
\hline $\begin{array}{l}\text { Contact with non- } \\
\text { ordinary beings }\end{array}$ & $25 \%$ & $*$ & $18 \%$ \\
\hline $\begin{array}{l}\text { Contact with } \\
\text { transcendent forces }\end{array}$ & $34 \%$ & $* * *$ & $20 \%$ \\
\hline Disgust & $5 \%$ & $* * *$ & $25 \%$ \\
\hline $\begin{array}{l}\text { Ego death or } \\
\text { dissolution }\end{array}$ & $34 \%$ & & $32 \%$ \\
\hline Fear & $24 \%$ & $* * *$ & $69 \%$ \\
\hline $\begin{array}{l}\text { Feeling of } \\
\text { homecoming or } \\
\text { return to your } \\
\text { essence }\end{array}$ & $61 \%$ & $* * *$ & $17 \%$ \\
\hline $\begin{array}{l}\text { Feeling of isolation } \\
\text { from other people }\end{array}$ & $13 \%$ & $* * *$ & $41 \%$ \\
\hline $\begin{array}{l}\text { Improved connection } \\
\text { with nature }\end{array}$ & $77 \%$ & $* * *$ & $18 \%$ \\
\hline $\begin{array}{l}\text { Improved connection } \\
\text { with other people }\end{array}$ & $69 \%$ & $* * *$ & $21 \%$ \\
\hline Inner visions & $58 \%$ & $* * *$ & $31 \%$ \\
\hline Insight into the world & $79 \%$ & $* * *$ & $30 \%$ \\
\hline $\begin{array}{l}\text { Insight into your } \\
\text { relations }\end{array}$ & $76 \%$ & $* * *$ & $33 \%$ \\
\hline Insight into yourself & $87 \%$ & $* * *$ & $39 \%$ \\
\hline Joy & $86 \%$ & $* * *$ & $19 \%$ \\
\hline Love & $78 \%$ & $* * *$ & $18 \%$ \\
\hline Peace & $84 \%$ & $* * *$ & $20 \%$ \\
\hline $\begin{array}{l}\text { Regrettable behavior } \\
\text { towards others }\end{array}$ & $7 \%$ & $* * *$ & $17 \%$ \\
\hline Sadness & $19 \%$ & $* * *$ & $44 \%$ \\
\hline Surprise & $43 \%$ & $* * *$ & $29 \%$ \\
\hline $\begin{array}{l}\text { Unity with } \\
\text { transcendent forces }\end{array}$ & $42 \%$ & $* * *$ & $16 \%$ \\
\hline Violent behavior & $\mathbf{0} \%$ & $* *$ & $4 \%$ \\
\hline $\begin{array}{l}\text { Words cannot } \\
\text { describe the } \\
\text { experience }\end{array}$ & $50 \%$ & $* *$ & $39 \%$ \\
\hline
\end{tabular}

Note: $N=214$. Stars indicates significant difference on the paired $t$ test between characteristics endorsed by respondents for a typical and their worst psychedelic experience: ${ }^{*} P \leq 0.05,{ }^{* *} P \leq 0.01$, ${ }^{* * *}$ $P \leq 0.001$. Rows in bold show characteristics endorsed at a higher percentage for respondents' worst psychedelic experience.

challenging experience, while $17 \%$ reported five or more negative characteristics. Respondents were also asked to estimate the relative difficulty of their worst psychedelic experience as compared to other difficult life experiences, with $6 \%$ declaring it the most difficult experience of their life, and a further $17 \%$ judging it one of their five most difficult life experiences (Fig. 1). At the other end of the scale, $26 \%$ stated that their worst psychedelic experience compared to an everyday or not difficult experience. Note that with this variable for relative difficulty, higher scores indicate lower difficulty. The indicators for absolute and relative difficulty of the worst psychedelic experience correlated strongly ( $r h o=-0.50, N=214, P<0.001$ ), but the relative assessment obviously depended upon the extent of other difficult life experiences, which the survey did not attempt to assess.

Ordinal regression was used to assess the impact of a range of predictor variables on these two indicators of experiential difficulty. The first indicator is labeled 'absolute difficulty', as it provides a difficulty score that is independent of other factors, while the second indicator is labeled 'relative difficulty' since it ranks the difficulty of the worst psychedelic experience relative to other difficult life experiences. The regression model for absolute difficulty was the strongest, with a Nagelkerke $\mathrm{R}^{2}$ of 0.34 (Table 3). In this model, both age and education, as controlled for the other variables, negatively predicted a difficult psychedelic experience, indicating that maturity and education reduce the difficulty of a challenging psychedelic experience. Female gender and the personality trait Emotional stability similarly served to reduce the number of negative characteristics. Perhaps surprisingly, meditation practice increased the difficulty of the experience, while practice involving energy work marginally reduced difficulty. One possible explanation for the effect from meditation is that meditators may be more accustomed to maintaining awareness of and labeling thoughts and emotions that arise in the mind, while individuals with energy practices may be skilled in diffusing negative states. The number of lifetime use occasions of the chosen psychedelic drug increased the difficulty of the worst experience, which we should probably understand to mean that the longer one uses psychedelics, the more likely one is to have a full-blown challenging experience. Years of cannabis experience, however, contributed to decrease difficulty. Finally, having an escapist motivation for psychedelics use served to increase the number of difficult characteristics. The regression model for relative difficulty was somewhat weaker, with a Nagelkerke $\mathrm{R}^{2}$ of 0.24 (see Table A1 in the online appendix). This model is congruent with the first model in that female gender, education and the personality trait Emotional stability reduced the difficulty of the experience, while the number of lifetime use occasions increased difficulty. The other significant variables from the first model did not reach the level of significance for this model, but it introduced the personality trait Openness as a predictor of more relatively difficult experiences. In neither of these models did the variables for social environment and the extent of planning for the psychedelic session affect the difficulty of the experience. It should be noted, however, that these variables represent the typical setting and planning for the respondent when using psychedelics rather than the setting and planning specifically for the difficult session.

\section{Consequences of challenging psychedelic experiences}

Respondents reported few negative long-term consequences of their worst psychedelic trip (Fig. 2). More than 67\% 


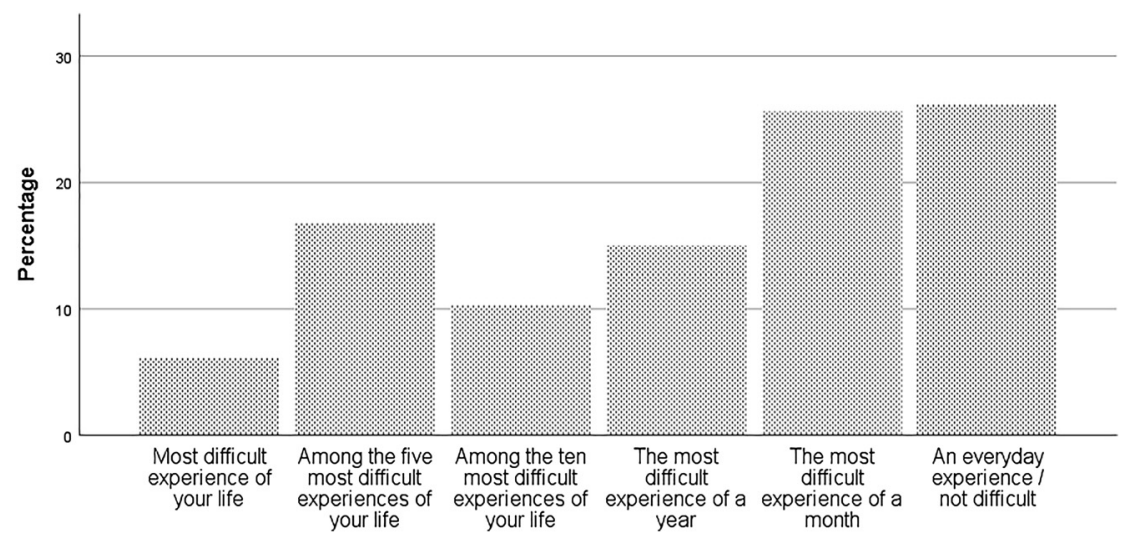

Fig. 1. Relative difficulty of respondents' worst psychedelic experience $(N=214)$

Table 3. Ordinal regression model for the absolute difficulty of a challenging psychedelic experience

\begin{tabular}{|c|c|c|c|c|}
\hline & Estimate & Standard error & Wald & Significance \\
\hline Age & -0.305 & 0.131 & 5.430 & 0.020 \\
\hline Gender $(\mathrm{F})$ & -0.751 & 0.365 & 4.231 & 0.040 \\
\hline Education & -0.334 & 0.115 & 8.476 & 0.004 \\
\hline Extraversion & -0.135 & 0.093 & 2.104 & 0.147 \\
\hline Conscientiousness & 0.025 & 0.105 & 0.058 & 0.810 \\
\hline Openness & 0.087 & 0.140 & 0.389 & 0.533 \\
\hline Agreeableness & 0.196 & 0.106 & 3.403 & 0.065 \\
\hline Emotional stability & -0.230 & 0.100 & 5.277 & 0.022 \\
\hline Risk taking (overall RTI) & 0.003 & 0.017 & 0.026 & 0.872 \\
\hline Practice: meditation & 0.696 & 0.284 & 6.004 & 0.014 \\
\hline Practice: energy work & -0.821 & 0.423 & 3.767 & 0.052 \\
\hline Practice: prayer & 0.649 & 0.399 & 2.642 & 0.104 \\
\hline Years of cannabis experience & -0.248 & 0.114 & 4.769 & 0.029 \\
\hline \multicolumn{5}{|l|}{ Psychedelic use social environment } \\
\hline - Alone & -0.515 & 0.898 & 0.329 & 0.566 \\
\hline - With a single partner & 0.009 & 0.910 & 0.000 & 0.992 \\
\hline - With a small group of friends & -0.606 & 0.900 & 0.453 & 0.501 \\
\hline - With friends and acquaintances & 0.096 & 0.988 & 0.009 & 0.922 \\
\hline Psychedelic use planning & 0.026 & 0.167 & 0.025 & 0.875 \\
\hline Lifetime psychedelic use occasions & 0.447 & 0.083 & 29.322 & 0.000 \\
\hline Escapist motivation & 1.089 & 0.542 & 4.036 & 0.045 \\
\hline
\end{tabular}

Note: $N=202$. The dependent variable is an additive construct summing negative characteristics of the respondents' worst psychedelic experience (range 0-8). For explanations of the independent variables in the model, see the main text. Values in bold represent statistically significant associations at $P \leq 0.05$. Model fit: $P<0.001$. Nagelkerke R-square for the model: 0.34 . Variance inflation factor (VIF) range $1.16-1.80$.

regarded the long-term consequences to be either positive or mostly positive, compared to less than $4 \%$ who regarded the consequences to be either negative or mostly negative. There was no significant correlation between the assessment of long-term consequences and either the relative (rho = $-0.11, N=214, P=0.10$ ) or the absolute (rho $=0.01, N=$ $214, P=0.92)$ difficulty of the worst psychedelic experience. A multivariate linear regression model that used the same independent variables as the previous models plus the indicator for absolute difficulty achieved an adjusted $\mathrm{R}^{2}$ of only 0.05 (see Table A2 in the online appendix). In this model, only the personality trait Openness and the indicator for an escapist motivation for psychedelics use reached the level of significance, with Openness predicting positive consequences and escapism predicting negative consequences.

\section{DISCUSSION}

The working hypotheses for this study were that challenging psychedelic experiences have a greater thematic range than what has been established in previous research, that set and setting are important but not decisive for the occurrence of challenging episodes, and that respondent-assessed consequences of these experiences are generally positive. With regards to thematic range, both the interview and survey data indicated that challenging psychedelic experiences 


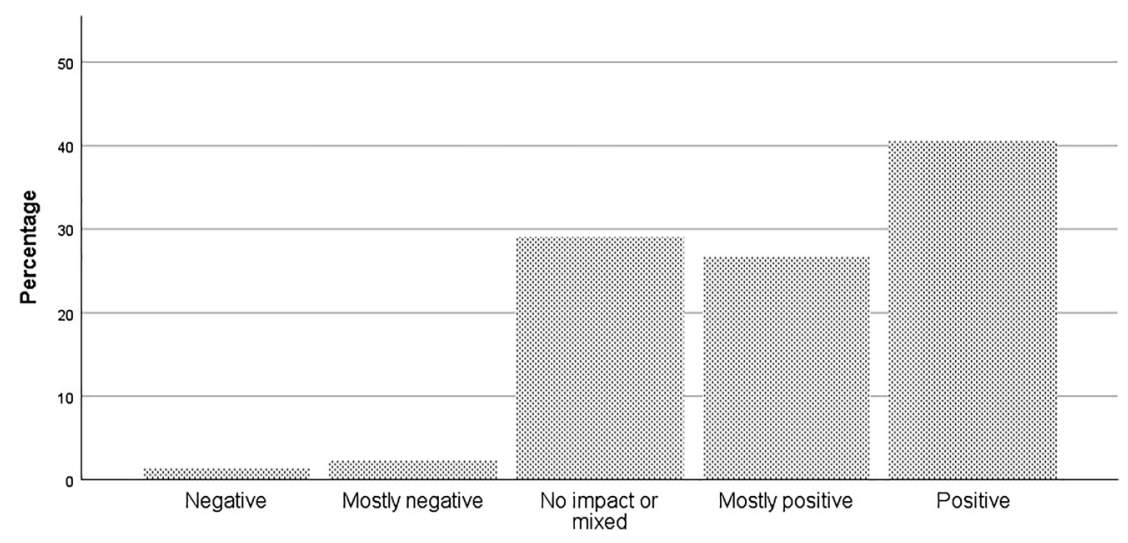

Fig. 2. Consequences of respondents' worst psychedelic experience $(N=214)$

come in a wide variety of types. The fear of ego dissolution that previous research has often emphasized (e.g., Studerus et al., 2012) was certainly an important aspect of many challenging psychedelic experiences in this study, but it was by no means a defining characteristic. In the survey data, ego dissolution was the only characteristic whose occurrence did not differ significantly between a typical and the respondents' worst psychedelic experience, and in the interviews, it was mentioned that ego dissolution could actually serve to protect the psychedelics user from other fear-inducing experiences. Furthermore, the types of challenging psychedelic experiences in this study seemed to have a greater range and variation than the seven categories of challenging experiences identified by Barrett et al. (2016). In the interview data, the theme identified as social paranoia overlaps with their category of paranoia, and their category of grief broadly overlaps with the theme identified as life issues, where the psychedelics user would have unpleasant insights into his or her life, usually accompanied by sadness, guilt, fear, and other unpleasant emotions. There is also an overlap between their categories of physical distress and death and the interview theme of physical damage, which sometimes led interviewees to believe that death was imminent. In Barrett et al.'s (2016) model, the category of isolation refers to loneliness and social isolation, which was not a major theme among the interviewees for the present study. Some, however, reported experiences of existential isolation where they felt eternally trapped in an inescapable void of nothingness. These experiences also relate to their category of insanity, which included the item "I was afraid that the state I was in would last forever" (Barrett et al., 2016, p. 22). This category seems somewhat underdefined, however, since it would also have to include experiences with dread of ego dissolution, where interviewees sometimes feared that they would lose their minds along with their egos, experiences with fear of having incurred lasting brain damage, and the one experience of an actual psychotic break. Furthermore, social paranoia, debilitating panic attacks, troubling visions or hallucinations, and delusions also relate to forms of insanity. The critique of under-definition is equally relevant for Barrett et al.'s (2016) category of fear, which was ubiquitous in these narratives, taking a range of forms that included fear of social rejection, existential fear, fear of insanity, fear of ego dissolution, fear of malicious entities, fear of death, and fear of eternal damnation. Thus, the interview data indicates that fear should probably be regarded more as a defining characteristic than a category of challenging psychedelic experiences: what makes the experience challenging is, above all, its ability to induce fear.

This emphasis on fear is supported by the survey data, where fear was the most endorsed characteristic for respondents' worst psychedelic experience at $69 \%$. If we factor in the $14 \%$ who endorsed none of the negative characteristics for their worst (or, in these cases, least good) experience, only $17 \%$ of the sample reported any negative characteristics without also reporting fear. Most of these experiences involved sadness (25 respondents), confusion (19 respondents), and isolation (12 respondents). Of course, a state of profound sadness could be regarded as a challenging experience in and of itself, and in principle, the same might be said even about an experience of overwhelming positive emotions. Therefore, it is not possible in principle to close off the set of challenging psychedelic experiences to any combination of defining characteristics, since there is no limit to what human beings might characterize as challenging. Nevertheless, fear seems to be so strongly interwoven with other characteristics of challenging psychedelic experiences that it could probably serve as an operationalized indicator of such experiences.

The survey data otherwise supports Barrett et al.'s (2016) categories of social isolation and grief as important aspects of challenging psychedelic experiences. Furthermore, about a third of the respondents indicated that their worst psychedelic experience involved insight into themselves or their relations, which is congruent with the theme of challenging life issues identified in interviews. The survey did not ask about physical distress, death, or insanity in a general sense, but $32 \%$ of respondents indicated that their worst experience included ego dissolution, which was significantly correlated with fear $(r=0.315, N=214, P<0.001)$. These were probably often experiences where respondents feared they would either lose their minds along with their egos (in other 
words, go insane), or lose their bodies along with their egos (in other words, die).

Beyond Barrett et al.'s (2016) seven categories, the survey identified confusion as an important characteristic of respondents' worst psychedelic trip, endorsed by $62 \%$. This was the highest level of endorsement for any characteristic except fear, which seems to indicate that confusion is a central aspect of challenging experiences. The indicator for confusion was significantly correlated with the indicator for ego dissolution $(r=0.297, N=214, P<0.001)$, which reflects the structure of Studerus et al.'s (2012) DED scale that included experiences of cognitive impairment and loss of self-control. Furthermore, the three characteristics anger or hate, regrettable behavior towards others, and violent behavior, which were all significantly correlated, seem to represent an important, if not very common, aspect of challenging psychedelic trips that has not been recognized in previous studies. The only corresponding narrative in the interview data was from the respondent who experienced a psychotic episode and attacked his friend. Although such violent episodes appear to be rare, $17 \%$ of the survey sample endorsed having behaved regrettably towards others, and it seems important to note that challenging psychedelic experiences sometimes have a behavioral aspect.

In the interviews, the most common form of challenging psychedelic experiences involved hard insights into one's life. The psychedelics user would be confronted with an aspect of their life that seemed dysfunctional, and although this confrontation was usually unpleasant at the time, it paved the way for important life changes. This dynamic may be relevant for the positive therapeutic effect from psychedelic experiences on issues of substance dependence (e.g., Bogenschutz et al., 2015; Johnson et al., 2014). However, some respondents also found themselves obsessing over minor life issues during psychedelic trips, in a manner that resembled paranoid delusion more than genuine insight. Newcomers to the psychedelic experience often found that the altered state allowed their minds to run wild with paranoid ideation, while more experienced users had usually learned to guide their minds in more fruitful directions, developing skills of focus and recollection that might be characterized as meditation skills.

The employment of meditation skills - although not necessarily recognized as such - in order to overcome challenging psychedelic experiences was quite widespread among interviewees. One example was the individual who recognized the powerful and malicious entity he encountered as a representation of his own anger, and was able to overcome his entrapment by this entity through a conscious release of this anger. Another participant found himself trapped in a reenactment of his high school years and was unable to open his eyes, yet managed to calm himself and to focus on what the experience had to offer, and others explicitly employed the skills obtained from their everyday meditation practice in order to overcome mental chaos and anxiety during psychedelic trips. It seems clear from these narratives that the process of learning how to navigate psychedelic trips involves the development of meditationtype skills, whether or not they are recognized as such. Nevertheless, it should be noted that the regression model for the absolute difficulty of a challenging psychedelic experience found that a meditation practice was actually associated with a more difficult experience when controlled for the other variables in the model. Possible explanations for this unexpected association may be that meditators are able to delve more deeply into the psychedelic experience, and are therefore confronted with more challenges, or perhaps that they are more mindful of their experiences and therefore able to identify a greater range of separate characteristics for them. This seems like a promising area for further research.

Factors relating to set and setting were not as important in these studies as we would perhaps expect. Set was the most salient of the two, and a number of interviewees pointed to negative aspects of their state of mind or emotions in order to explain the occurrence of their challenging trip. In most reports, however, there was no clear link between a negative mind-state before the psychedelic session and the emergence of challenging material during the session. Furthermore, interviewees rarely mentioned the setting of their psychedelics use as a factor that might explain their challenging experience. The survey did not attempt to assess participants' state of mind prior to the psychedelic session, but the variable for one's most common social environment during psychedelics use did not reach statistical significance in the regression model. It is possible, however, that the difficult experience they were asked to characterize took place in a very different social environment than the typical setting for their psychedelics use. This complicates the interpretation of the null finding for the impact from social environment in the regression analyses.

A majority of the participants in these studies found that their challenging experience resulted in positive long-term consequences, which agrees with previous research (Carbonaro et al., 2016). A small minority of $4 \%$ pointed to negative consequences, however, and $29 \%$ regarded the long-term impact as either irrelevant or mixed. This finding may be taken as support for Lucas' (2005) point that challenging psychedelic experiences only have positive consequences when the user is able to work with and integrate their hard lessons.

The main limitations of this explorative study were that participants were recruited via online psychedelic communities, and had to self-select for participation. It has previously been found that participants recruited on the Internet have more education and higher incomes (Hamilton \& Bowers, 2006), which might potentially bias findings. While the Internet is probably more accessible to those with lower education and income levels today than it was in 2006, the Internet recruitment in this study may have served to exclude some psychedelics users. More specifically, it is difficult to know to which extent this sample of psychedelics users represents the population of such users, about which we arguably know very little (Johnstad, 2021f). Furthermore, the study recruited mainly among current psychedelics 
users, who as a group are probably favorably inclined towards such drug use, and should therefore be considered biased towards positive results.

\section{CONCLUSION}

These explorative studies expanded the range of challenging psychedelic experiences beyond what has previously been described in academic literature, and identified paradoxical effects from meditation practices on the difficulty of such experiences. They identified fear as the most common aspect of challenging experiences, while also noting the importance of confusion and identifying a behavioral aspect that should not be ignored. Challenging psychedelic experiences were sometimes extremely difficult, but it should also be noted that a sizeable number of respondents had never faced a difficult experience at all. Fewer than $4 \%$ of respondents reported that the long-term consequences of the experience were negative.

\section{SUPPLEMENTARY MATERIALS}

Supplementary data to this article can be found online at https://doi.org/10.1556/2054.2021.00155.

\section{REFERENCES}

Barrett, F., Bradstreet, M., Leoutsakos, J., Johnson, M., \& Griffiths, R. (2016). The Challenging Experience Questionnaire: Characterization of challenging experiences with psilocybin mushrooms. Journal of Psychopharmacology, 30, 1279-1295. https:// doi.org/10.1177/0269881116678781.

Bogenschutz, M., Forcehimes, A., Pommy, J., Wilcox, C., Barbosa, P., \& Strassman, R. (2015). Psilocybin-assisted treatment for alcohol dependence: A proof-of-concept study. Journal of Psychopharmacology, 29(3), 289-299. https://doi.org/10.1177/ 0269881114565144.

Braun, V., \& Clarke, V. (2006). Using thematic analysis in psychology. Qualitative Research in Psychology, 3, 77-101. https:// doi.org/10.1191/1478088706qp063oa.

Carbonaro, T., Bradstreet, M., Barrett, F., MacLean, K., Jesse, R., Johnson, M., et al. (2016). Survey study of challenging experiences after ingesting psilocybin mushrooms: Acute and enduring positive and negative consequences. Journal of Psychopharmacology, 30, 1268-1278. https://doi.org/10.1177/ 0269881116662634.

Carhart-Harris, R., Bolstridge, M., Day, C., Rucker, J., Watts, R., Erritzoe, D., Nutt, D., et al. (2018). Psilocybin with psychological support for treatment-resistant depression: Six-month follow-up. Psychopharmacology, 235, 399-408. https://doi.org/ 10.1007/s00213-017-4771-x.

Carhart-Harris, R., Bolstridge, M., Rucker, J., Day, C., Erritzoe, D., Kaelen, M., Nutt, D., et al. (2016). Psilocybin with psychological support for treatment-resistant depression: An open-label feasibility study. Lancet Psychiatry, 3, 619-627. https://doi.org/ 10.1016/S2215-0366(16)30065-7.

Carhart-Harris, R., Erritzoe, D., Haijen, E., Kaelen, M., \& Watts, R. (2017). Psychedelics and connectedness. Psychopharmacology, 235, 547-550. https://doi.org/10.1007/s00213-017-4701-y.

Carhart-Harris, R., \& Nutt, D. (2010). User perceptions of the benefits and harms of hallucinogenic drug use: A web-based questionnaire study. Journal of Substance Abuse, 15, 283-300. https://doi.org/10.3109/14659890903271624.

Cohen, S. (1960). Lysergic acid diethylamide: Side effects and complications. The Journal of Nervous and Mental Disease, 130, 30-40. https://doi.org/10.1097/00005053-19600100000005.

Dobkin de Rios, M. (1990). Hallucinogens: Cross-cultural perspectives. Prospect Heights, IL: Waveland Press.

Gasser, P., Holstein, D., Michel, Y., Doblin, R., Yazar-Klosinski, B., Passie, T., et al. (2013). Safety and efficacy of lysergic acid diethylamide-assisted psychotherapy for anxiety associated with life-threatening diseases. The Journal of Nervous and Mental Disease, 202, 513-520. https://doi.org/10.1097/NMD.00000000 00000113.

Gosling, S. D., Rentfrow, P. J., \& Swann, W. B. (2003). A very brief measure of the Big-Five personality domains. Journal of Research in Personality, 37(6), 504-528. https://doi.org/10. 1016/S0092-6566(03)00046-1.

Griffiths, R., Johnson, M., Carducci, M., Umbricht, A., Richards, W., Richards, B., Klinedinst, M., et al. (2016). Psilocybin produces substantial and sustained decrease in depression and anxiety in patients with life-threatening cancer: A randomized double-blind trial. Journal of Psychopharmacology, 30, 11811197. https://doi.org/10.1177/0269881116675513.

Griffiths, R., Richards, W., McCann, U., Jesse, R. (2006). Psilocybin can occasion mystical-type experiences having substantial and sustained personal meaning and spiritual significance. Psychopharmacology, 187, 268-283. https://doi.org/10.1007/s00213011-2358-5.

Grob, C., Danforth, A., Chopra, G., Hagerty, M., McKay, C., Halberstadt, A., et al. (2011). Pilot study of psilocybin treatment for anxiety in patients with advanced-stage cancer. Archives of General Psychiatry, 68(1), 71-78. https://doi.org/10.1001/ archgenpsychiatry.2010.116.

Hamilton, R. J. \& Bowers, B. J. (2006). Internet recruitment and email interviews in qualitative studies. Qualitative Health Research, 16, 821-835. https://doi.org/10.1177/1049732306287599.

Hartogsohn, I. (2017). Constructing drug effects: A history of set and setting. Drug Science, Policy and Law, 3, 1-19. https://doi. org/10.1177/2050324516683325.

Hendricks, P. S., Thorne, C. B., Clark, C. B., Coombs, D. W., \& Johnson, M. W. (2015). Classic psychedelic use is associated with reduced psychological distress and suicidality in the United States adult population. Journal of Psychopharmacology, 29(3), 280-288. https://doi.org/10.1177/0269881114565653.

Hultkrantz, A. (1997). The attraction of peyote. Stockholm: Almqvist \& Wiksell.

Johnson, M., Garcia-Romeu, A., Cosimano, M., \& Griffiths, R. (2014). Pilot study of the 5-HT2AR agonist psilocybin in the treatment of tobacco addiction. Journal of Psychopharmacology, 28, 983-992. https://doi.org/10.1177/0269881114548296. 
Johnstad, P. (2018). Entheogenic spirituality: Exploring spiritually motivated entheogen use among modern Westerners. Journal of Ethnographic and Qualitative Research, 12, 244-260.

Johnstad, P. (2020a). A dangerous method? Psychedelic therapy at Modum Bad, Norway, 1961-76. History of Psychiatry, 31, 217226. https://doi.org/10.1177/0957154X19894537.

Johnstad, P. G. (2020b). Cannabis and Psychedelics User Survey questionnaire and dataset (figshare). https://doi.org/10.6084/ m9.figshare.13121846.v1.

Johnstad, P. G. (2020c). Cannabis as entheogen: Survey and interview data on the spiritual use of cannabis. Journal of Cannabis Research, 2(30), 1-17. https://doi.org/10.1186/s42238-02000032-2.

Johnstad, P. G. (2021a). Entheogenic experience and spirituality. Methods and Theory in the Study of Religion. Advance online publication. https://doi.org/10.1163/15700682-12341512.

Johnstad, P. G. (2021b). Entheogenic spirituality: characteristics of spiritually motivated psychedelics use. Manuscript submitted for publication.

Johnstad, P. G. (2021c). Psychedelic woman: Gender differences in entheogenic spirituality. Manuscript submitted for publication.

Johnstad, P. G. (2021d). The psychedelic personality: Personality structure and associations in a sample of psychedelics users. Journal of Psychoactive Drugs, 53(2), 97-103. https://doi.org/10. 1080/02791072.2020.1842569.

Johnstad, P. G. (2021e). Who is the typical psychedelics user? Methodological challenges for research on psychedelics use and its consequences. Nordic Studies on Alcohol and Drugs, 38(1), 35-49. https://doi.org/10.1177/1455072520963787.

Kvale, S., \& Brinkmann, S. (2015). InterViews: Learning the craft of qualitative research interviewing. Los Angeles, CA: Sage.

Labate, B., \& Cavnar, C. (Eds.). (2014). Ayahuasca shamanism in the Amazon and beyond. New York, NY: Oxford University Press.

Lucas, M. (2005). On not passing the acid test: Bad trips and initiation. Anthropology of Consciousness, 16(1), 25-50. https:// doi.org/10.1525/ac.2005.16.1.25.

Lyvers, M., \& Meester, M. (2012). Illicit use of LSD or psilocybin, but not MDMA or nonpsychedelic drugs, is associated with mystical experiences in a dose-dependent manner. Journal of Psychoactive Drugs, 44, 410-417. https://doi.org/10.1080/ 02791072.2012 .736842$.

Majić, T., Schmidt, T., \& Gallinat, J. (2015). Peak experiences and the afterglow phenomenon: When and how do therapeutic effects of hallucinogens depend on psychedelic experiences? Journal of Psychopharmacology, 29, 241-253. https://doi.org/10. 1177/0269881114568040.

Maroukis, T. (2012). The peyote road: Religious freedom and the Native American Church. Norman, OK: University of Oklahoma Press.

Nichols, D. (2004). Hallucinogens. Pharmacology \& Therapeutics, 101, 131-181. https://doi.org/10.1016/j.pharmthera.2003.11.002.
Nichols, D. (2016). Psychedelics. Pharmacological Reviews, 68, 264-355. https://doi.org/10.1124/pr.115.011478.

Nicholson, N., Soane, E., Fenton-O'Creevy, M., \& Willman, P. (2005). Personality and domain-specific risk taking. Journal of Risk Research, 8(2), 157-176. https://doi.org/10.1080/136698 7032000123856.

Nour, M., Evans, L., Nutt, D., \& Carhart-Harris, R. (2016). Egodissolution and psychedelics: Validation of the ego-dissolution inventory (EDI). Frontiers in Human Neuroscience, 10, 1-16. https://doi.org/10.3389/fnhum.2016.00269.

Nour, M. M., Evans, L., \& Carhart-Harris, R. L. (2017). Psychedelics, personality and political perspectives. Journal of Psychoactive Drugs, 49(3), 182-191. https://doi.org/10.1080/02791072.2017. 1312643.

Ona, G. (2018). Inside bad trips: Exploring extra-pharmacological factors. Journal of Psychedelic Studies, 2(1), 53-60. https://doi. org/10.1556/2054.2018.001.

Pahnke, W. (1966). Drugs and mysticism. International Journal of Parapsychology, 8, 295-320.

Ross, S., Bossis, A., Guss, J., Agin-Liebes, G., Malone, T., Cohen, B., et al. (2016). Rapid and sustained symptom reduction following psilocybin treatment for anxiety and depression in patients with life-threatening cancer: A randomized controlled trial. Journal of Psychopharmacology, 30, 1165-1180. https://doi.org/10.1177/ 0269881116675512.

Rubinow, D., \& Cancro, R. (1977). The bad trip: An epidemiological survey of youthful hallucinogen use. Journal of Youth and Adolescence, 6(1), 1-9. https://doi.org/10.1007/BF02138920.

Rucker, J., Iliff, J., \& Nutt, D. (2018). Psychiatry \& the psychedelic drugs: Past, present \& future. Neuropharmacology, 142, 200218. https://doi.org/10.1016/j.neuropharm.2017.12.040.

Schenberg, E., de Castro Comis, M., Chaves, B., \& da Silveira, D. (2014). Treating drug dependence with the aid of ibogaine: A retrospective study. Journal of Psychopharmacology, 28, 993-1000. https://doi.org/10.1177/0269881114552713.

Shulgin, A., \& Shulgin, A. (1991). PIHKAL: A chemical love story. Berkeley, CA: Transform Press.

Shulgin, A., \& Shulgin, A. (1997). TIHKAL: The continuation. Berkeley, CA: Transform Press.

Studerus, E., Gamma, A., Kometer, M., \& Vollenweider, F. (2012). Prediction of psilocybin response in healthy volunteers. PloS One, 7(2), e30800. https://doi.org/10.1371/journal.pone. 0030800.

Thomas, G., Lucas, P., Capler, N., Tupper, K., \& Martin, G. (2013). Ayahuasca-assisted therapy for addiction: Results from a preliminary observational study in Canada. Current Drug Abuse Reviews, 6, 30-42.

Ungerleider, J., Fisher, D., Fuller, M., \& Caldwell, A. (1968). The "bad trip" - The etiology of the adverse LSD reaction. American Journal of Psychiatry, 124, 1483-1489. https://doi.org/10.1176/ ajp.124.11.1483.

\footnotetext{
Open Access. This is an open-access article distributed under the terms of the Creative Commons Attribution-NonCommercial 4.0 International License (https:// creativecommons.org/licenses/by-nc/4.0/), which permits unrestricted use, distribution, and reproduction in any medium for non-commercial purposes, provided the original author and source are credited, a link to the CC License is provided, and changes - if any - are indicated.
} 